\title{
Reações comunicativas dos alunos de enfermagem frente ao primeiro estágio curricular
}

\author{
COMMUNICATIVE REACTIONS OF NURSING STUDENTS REGARDING THEIR \\ FIRST CURRICULAR INTERNSHIP PERIOD
}

REACCIONES DE COMUNICACIÓN EN LOS ALUMNOS DE ENFERMERÍA FRENTE
A LA PRIMERA PRÁCTICA CURRICULAR

Lívia Silva Bosquetti ${ }^{1}$, Eliana Mara Braga ${ }^{2}$

\section{RESUMO}

Este estudo tem como objetivo descrever as reações que os alunos de enfermagem apresentaram quando do seu primeiro estágio curricular. É um estudo transversal e de campo, e o tratamento dos dados foi realizado com base no método de análise de conteúdo. Os resultados descrevem o campo de estágio, o relacionamento com a equipe da enfermaria, com os pacientes e com o docente durante este período. Nas conclusões, podemos afirmar que o estresse e as contradições vivenciadas no primeiro estágio são parte do crescimento e aprendizado do aluno. $O$ professor é maior responsável por determinar o tipo de interação que haverá entre ele e o aluno, cabendo-lhe ouvir, incentivar e capacitar-se para apoiar os alunos nas experiências iniciais da prática, para que o primeiro estágio seja um fator motivador ao aluno.

\section{DESCRITORES}

Comunicação.

Relações interpessoais.

Educação em enfermagem.

Bolsas e estágios.

\begin{abstract}
The objective of the present study is to describe and analyze the reactions of nursing students, presented during their first curricular internship. It is a cross-section field study, with data analyzed according to the method of content analysis. The results describe the training field, the relationship with the nursing team, the patients and the professor in the period of training. In the conclusions, we can affirm that the stress and the contradictions experienced in the first period of internship are part of the student's growth and education. The professor is responsible for determining the type of interaction that the students will experience. He/She needs to be capable of listening, encouraging and for his/her own qualification, in order to support the students with the early experiences of the practice, so that the first internship a becomes motivating factor for the students.
\end{abstract}

\section{KEY WORDS}

Communication.

Interpersonal relations.

Education, nursing.

Fellowships and internships.

\section{RESUMEN}

Estudio que tiene por objetivo describir las reacciones que los alumnos de enfermería mostraron durante su primera práctica curricular. Investigación transversal y de campo. El análisis de los datos realizado en base al método de análisis de contenido. Los resultados describen durante este periodo el campo de práctica, la relación con el equipo de enfermería, con los pacientes y con el enfermo. Concluimos que el estrés y los obstáculos vividos durante esta primera práctica son parte del crecimiento y aprendizaje del alumno. El profesor es el mayor responsable por determinar el tipo de interacción establecida entre él y el alumno, responsabilizándose por escuchar, incentivar, capacitar y apoyar a los alumnos durante sus primeras experiencias prácticas, para que este momento sea un factor motivador para el alumno.

\section{DESCRIPTORES}

Comunicación.

Relaciones interpersonales.

Educación en enfermería.

Becas y pasantías. 


\section{INTRODUÇÃO}

Este trabalho tratará das reações dos alunos de enfermagem ao vivenciarem o primeiro estágio curricular, pois acreditamos ser importante conhecer essas manifestações para que os professores possam trabalhar melhor os medos, as ansiedades e as emoções que os alunos sentem quando entram em contato com o ambiente hospitalar.

A entrada brusca dos alunos numa situação desconhecida é fator desencadeante de tensões e ansiedades e estes sentimentos interferem de modo negativo no aprendizado sendo imprescindível que o docente em campo de estágio esteja consciente disso e tenha atitudes de compreensão para com o aluno. Este universo de reações acontece, especialmente, no primeiro estágio curricular e gera ansiedade no aluno, além de uma situação desconfortável para o professor. De acordo com estudo realizado, a maioria dos alunos entrevistados expressa ansiedade com relação aos procedimentos técnicos e nos relacionamentos com o paciente e docente $\mathrm{e}^{(1)}$.

O início da prática de enfermagem representa para o aluno uma vivência difícil e frustrante. Esse processo pode ser facilitado quando o iniciante identifica ajuda na interação com o professor ${ }^{(2)}$. Os procedimentos de enfermagem, o professor, o campo de estágio, o médico, o colega, o paciente, o tempo e a enfermeira são elementos que aparecem como os principais responsáveis pelas impressões que os alunos têm do primeiro contato com a prática profissional, sendo que o papel do professor se destaca nestas impressões ${ }^{(3)}$.

O primeiro estágio curricular que introduz o aluno na prática propicia ao graduando experimentar sentimentos ambivalentes: por um lado, ele iniciará o estágio e sentir-se-á, pela primeira vez, inserido na profissão; por outro ele experimentará a angústia relatada por colegas que já fizeram a disciplina(4).

As dificuldades e angústias que o aluno vivencia no relacionamento com o paciente, o professor e o ambiente produzem efeitos positivos e negativos referentes às primeiras experiências práticas do aluno junto aos pacientes. Nos relatos negativos estão fatores como cuidar do paciente de alta complexidade, presenciar a morte, além da percepção dos alunos de que os profissionais da área de saúde são insensíveis à dor, à morte e ao morrer. Como relatos positivos, observa-se que a prestação de assistência de enfermagem à pacientes de alta complexidade permitiu o desenvolvimento de procedimentos mais complexos e assistência integral e quando os alunos cuidaram de pacientes graves que se recuperaram, foi identificada uma grande satisfação por parte dos mesmos. Cabe ressaltar que os relatos positivos foram acompanhados de conduta compreensiva do professor ${ }^{(4)}$.

O professor deve estimular o interesse dos alunos, considerando os aspectos psicológicos envolvidos no processo ensino-aprendizagem, pois tanto o professor como o aluno, revelam qualidades que facilitam a comunicação, mas também traços negativos que dificultam o relacionamento(5).

Neste sentido, o professor precisa se perceber como pessoa e não só como um profissional, pois o professor é o maior responsável por determinar o tipo de interação que haverá entre ele e o aluno. Neste contexto, o aluno deve ser compreendido como aquele que precisa aprender e por isso, buscar o conhecimento do professor. Resultados de estudo demonstram que o aluno espera ser ouvido e respeitado em suas opiniões, além de receber incentivo à participação e contar com uma boa dinâmica em sala de aula ${ }^{(5)}$.

Em todos os trabalhos descritos acima, foram identificadas as dificuldades dos alunos e relatadas suas experiências, sendo notável a importância do professor nessa fase inicial de aprendizagem.

Diante disso, temos como objetivos neste estudo descrever as reações que os alunos de enfermagem apresentaram quando do seu primeiro estágio curricular, além de verificar as opiniões dos alunos em função do campo de estágio, equipe de trabalho, do paciente e na relação com o docente.

\section{MÉTODO}

A pesquisa foi desenvolvida como um estudo transversal e de campo com alunos no primeiro estágio prático em enfermarias de um Hospital Público.

A população deste estudo foi constituída por quarenta e nove alunos do terceiro e quarto anos da graduação de enfermagem. Optamos por estes alunos, porque já tiveram a oportunidade de cursar disciplinas e realizar atividades práticas com pacientes em enfermarias.

Iniciamos o estudo encaminhando o projeto de pesquisa para ciência e autorização do Conselho da Graduação em Enfermagem. Após esta autorização, encaminhamos o projeto de pesquisa ao Comitê de Ética em Pesquisa da Faculdade de Medicina de Botucatu - UNESP do qual recebeu parecer favorável (Ofício no 305/2005-CEP), em seguida entramos em contato com os sujeitos envolvidos neste estudo para expor o objetivo da pesquisa e solicitar Consentimento Livre e Esclarecido para a participação nesta pesquisa. Os dados foram coletados no segundo semestre do ano de 2005.

A participação neste estudo foi voluntária, sendo que todos os alunos do terceiro ano participaram da pesquisa, totalizando 30 alunos, e somente 19 alunos dos 30 alunos do quarto ano participaram.

Após o consentimento dos alunos para a pesquisa, foi entregue a cada um, um formulário com questões descritivas sobre enfermaria em que se realizou o estágio, o relacionamento com a equipe, os pacientes e o docente. Os alunos res- 
ponderam as questões no momento da entrega do formulário, posteriormente nos devolvendo o material do estudo.

O tratamento dos dados foi realizado pela interpretação das respostas do formulário, com base no método qualitativo de análise de conteúdo.

A análise de conteúdo é um conjunto de técnicas de análise das comunicações visando obter, por procedimentos sistemáticos e objetivos de descrição do conteúdo das mensagens, indicadores, quantitativos ou não, que permitam a inferência de conhecimentos relativos às condições de produção/recepção (variáveis inferidas) destas mensagens. Este método é composto de três fases: pré-análise, exploração do material, tratamento dos resultados, a inferência e a interpretação( ${ }^{(6)}$.

\section{RESULTADOS E DISCUSSÃO}

Apresentaremos os dados, a partir das questões formuladas aos sujeitos da pesquisa.

\section{Descrevendo a enfermaria em que realizou seu primeiro estágio:}

\section{Enfermaria com diversidade de procedimentos}

Os alunos referem-se a variedade de procedimentos por considerarem que a enfermaria em que realizaram o primeiro estágio, ofereceu-lhes inúmeras oportunidades de realizarem procedimentos:

era um ambiente tranqüilo e rico em procedimentos a serem feitos (E.2), dinâmica e com ampla variedade de procedimentos simples (E.18), rica em procedimentos (E.32, boas oportunidades para realização de técnicas (E.43).

\section{Enfermaria confusa, desorganizada, sem planejamento}

Os alunos consideram nessa questão que a enfermaria em que realizaram seu primeiro estágio era desorganizada, por não ter sala para estagiários, e por ter a organização diferente da ensinada durante as aulas:

é muito confusa (E.6), quartos amplos, com muitos leitos, dando a impressão de pessoas amontoadas, um pouco bagunçada (E.15), não tinha espaço suficiente para nós. A sala de prescrição médica era muito pequena e a salinha de enfermagem acabava acomodando a nós estagiários e aos funcionários (E.23), é uma boa enfermaria, embora falte espaço para um atendimento individualizado como uma sala para conversar com paciente e família (E.27).

Em contrapartida, alguns alunos consideraram que a enfermaria em que realizaram o primeiro estágio era bem planejada e organizada, considerando que tudo o que procuravam logo era encontrado.

Cabe ressaltar que os alunos participantes da pesquisa foram divididos em dois grupos de estágio, passando em enfermarias diferentes, o que nos fez encontrar resultados como:

uma enfermaria das mais organizadas, tudo que se procurava estava no lugar, facilitando e agilizando os nossos cuidados (E.7,8,13,22,23)

O planejamento é um instrumento do processo do trabalho gerencial que pode ser definido como a arte de fazer escolhas e de elaborar planos para favorecer um processo de mudança. Contudo, se os instrumentos que estivermos utilizando para operar na realidade não forem os mais apropriados, o objetivo almejado pode não ter a direção desejada, assim como a produção de serviços com qualidade pode ser prejudicada ${ }^{(7)}$.

\section{Enfermaria difícil por requerer muito esforço físico}

Os alunos relataram que os pacientes exigiam muitos cuidados braçais, resultando em um grande esforço físico, durante o estágio:

um pouco pesada, já que os pacientes exigiam muitos cuidados (E.38), pesada, pois a clientela exige cuidados braçais (E.42), campo de prática muito difícil, pois exigia um grande esforço físico (E.47).

A Organização Mundial da Saúde admite que os problemas ergonômicos, como lombalgias e problemas na coluna vertebral, característicos de hospitais parecem ser a movimentação e o transporte de pacientes ${ }^{\left({ }^{()}\right.}$.

\section{Enfermaria como um ambiente causador de estresse}

Os alunos classificaram a enfermaria como triste, devido a falta de iluminação, tornando-a escura, por ter mau cheiro, além de internar pacientes com patologias graves e sem um bom prognóstico, causando estresse no primeiro estágio:

\section{era tudo novo, legal e estranho ao mesmo tempo. Foi uma das melhores enfermarias que passei até agora (E.1), não era capaz de perceber os defeitos da enfermaria (E.2), ela é meio suja e tem um cheiro ruim (E.3), sempre há um estresse no primeiro estágio(E.17), tensão por ser o pri- meiro estágio (E.19).}

O estresse tem sido visto como o resultado do embate entre determinada dificuldade e a capacidade individual de superá-la, suas conseqüências vinculam-se estreitamente à resposta individual diante de determinada demanda, ou seja, aquilo que para alguns é percebido e vivenciado como um desafio estimulante, gratificante, a ponto de ser buscado, para outros pode ser interpretado como uma grande ameaça a ser enfrentada ${ }^{(9)}$.

\section{Enfermaria desestimulante}

Os alunos relataram que a maioria das atividades realizadas no primeiro estágio eram banhos no leito, o que era considerado por eles como desestimulante: 
enfermaria muito desestimulante pelo fato das ações de nós alunas, se restringirem a banhos de leito (E.37), nesse estágio aprendi banho no leito, pois quase todos pacientes eram acamados (E.38), um bom campo para se aprender banho no leito (E.45).

Entendemos que os alunos deram pouca importância à técnica de banho no leito, por ser um procedimento que não exige conhecimento técnico complexo, porém eles o consideram trabalhoso.

Seria importante a motivação do aluno para que essa técnica não se torne rejeitada por eles.

Atitudes profissionais como indiferença, descompromisso e falta de motivação, são consideradas decorrentes de dificuldades no desenvolvimento do trabalho de enfermagem, devendo ser ressaltada a necessidade do desenvolvimento da sensibilidade, visando a melhoria da assistência

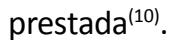

\section{Descrevendo o relacionamento com a equipe da enfermaria}

\section{Relacionamento cooperativo}

Os alunos relatam que os funcionários da enfermaria foram receptivos, atenciosos e sempre ajudavam:

a equipe, os funcionários em geral foram bastante receptivos e sempre estavam dispostos a ensinar alguma técnica, uma patologia, entre outras coisas (E. 7), a equipe no geral foi muito solicita, ajudando sempre que surgia alguma dúvida, com isso ajudando no andamento do estágio (E. 14), quando solicitada ajuda, sempre havia disponibilidade (E. 18).

\section{Relacionamento tímido}

Os alunos relatam que por ser o primeiro contato com a equipe de enfermagem, o relacionamento foi tímido, tiveram insegurança em se relacionar com os funcionários, ficavam mais observando. Porém, alguns alunos relatam que houve pouco contato com a equipe, pois eles deixavam os alunos sozinhos e abandonavam a enfermaria durante o período do estágio:

no início eu estava um pouco tímida, não tinha coragem de perguntar nada, mas com o passar do tempo o relacionamento foi melhorando e eu fiquei mais comunicativa (E.4), talvez por ter sido a primeira experiência o relacionamento foi distante e tímido, eu estava lá para aprender e mais observava do que opinava (E.9), não tive nenhum problema, principalmente porque os funcionários somem quando nós chegamos (E.27), na realidade não houve um relacionamento efetivo, porém nunca fui mal tratada (E.33).

\section{Relação de simples transmissão de informações}

Os alunos relatam que a equipe era prestativa, mas que os tratavam como aprendizes e abusavam dos alunos na realização dos cuidados diários. Muitas vezes, queriam en- sinar os procedimentos como se eles (os alunos) não tivessem conhecimento algum:

senti que eu era vista como uma simples aprendiz, cada um queria explicar as coisas a seu modo, porque julgavam que de qualquer maneira sabiam mais do que eu (E. 6), a equipe era bastante prestativa, mas tinha umas manias de querer mandar ou ensinar a gente, o que muitas vezes gerava briga entre os funcionários e as professoras (E.23), foi razoável, pois no primeiro estágio, desenvolvíamos apenas os cuidados, como banho, alimentação, limpeza e os funcionários acabavam vendo as alunas como "escravas" (E.31).

A compreensão do ser humano é o ponto fundamental para o desenvolvimento pessoal e profissional. Deve ser realizado por intermédio de um processo educativo, que tenha vivencia e interesse, onde o ser humano veja sua existência reconhecida nas relações que mantém com o outro $^{(11)}$.

\section{Relacionamento difícil}

Os alunos consideram que o relacionamento com a equipe foi difícil pois não tiveram contato com médicos e os auxiliares e técnicos de enfermagem não foram receptivos:

era bem difícil, eles eram bem fechados, me sentia muito perdida e quando pedia informações, não davam e quando davam era com cara feia e informação insuficiente ( $E$. 1), achei que não havia muita abertura e receptividade em relação aos alunos (E.18), no início é sempre difícil, mas depois de um tempo o relacionamento melhorou e a equipe ofereceu grande apoio (E.4).

Grupo é um conjunto de pessoas movidas por necessidades semelhantes que se reúnem em torno de uma tarefa específica ${ }^{(12)}$. No nosso caso, a equipe de enfermagem está toda envolvida em prestar assistência ao paciente.

Em estudo realizado numa instituição de ensino pública, os alunos de vários cursos da área da saúde apontaram como o principal facilitador da comunicação no trabalho em grupo, a boa interação profissional e as dificuldades para a comunicação em grupo foram falta de interação profissional e pessoal e na indefinição de papéis e responsabilidades ${ }^{(13)}$.

Verificamos que os alunos precisam receber apoio da equipe como um todo para sentirem-se mais seguros em realizar as tarefas propostas.

\section{Descrevendo o relacionamento com os pacientes}

\section{Bom relacionamento}

Os alunos relatam que o relacionamento deles com os pacientes foi proveitoso e terapêutico, os pacientes os aceitaram bem e não tiveram problemas:

muito bom, conheci pessoas maravilhosas, com histórias de vida muito peculiares e interessantes (E. 6), foi muito bom, consegui abordar bem todos os pacientes sob minha responsabilidade e fui muito bem aceita também (E. 13), o 
relacionamento com os pacientes foi muito bom, proveitoso e terapêutico (E. 23), o relacionamento com os pacientes foi muito gratificante (E.26), foi muito bom, vivi experiências para minha vida profissional e também pessoal (E.43).

\section{Relacionamento de ansiedade e insegurança}

Os alunos referiram sentir ansiedade e insegurança para realizarem os procedimentos, principalmente por este ser o primeiro contato com os pacientes e também por terem medo que os pacientes não os aceitassem:

\begin{abstract}
tinha um bloqueio no primeiro momento de chegar até o paciente e isto me deixou com medo de fazer os procedimentos, tinha medo deles não gostarem de mim (E. 1), foi diferente, já que era o primeiro estágio, nós não sabíamos abordar o paciente e tínhamos muitas dúvidas, e os pacientes percebiam, com isso ficavam desconfiados com os nossos cuidados (E.14), eles tinham uma boa aceitação do nosso tratamento e nossa presença (E. 18), tive medo nos primeiros contatos, sobretudo no que diz respeito a eles me virem como incompetente e atrapalhando os cuidados (E. 25), sempre compreensivos e sempre colaboravam para que nós prestássemos os cuidados (E. 47), foi com um pouco de ansiedade, no começo, mas com o decorrer do estágio foi se tornando tranqüilo, havia uma ansiedade com relação aos procedimentos a serem realizados (E. 48).
\end{abstract}

\section{Relacionamento difícil}

Os alunos consideraram o relacionamento difícil devido a algumas barreiras encontradas, como os vários sentimentos que sentiram, lidar com pacientes graves e por ter que lidar com a morte:

foi difícil, já que experimentamos vários sentimentos ao mesmo tempo, sem estarmos preparadas o suficiente para isso. Foram sentimentos de aceitação, raiva muitas vezes, piedade, entre outros. É o momento em que a gente realmente começa a se conhecer e a entender o nosso papel (E.19), foi difícil lidar com os pacientes, pois quase todos estavam em estado grave, encontrava-os depressivos, mal-humorados, angustiados e com medo (E. 22), desenvolvíamos pequenos vínculos, devido ao pouco tempo de internação da maioria dos pacientes, que como todos os outros que freqüentam a instituição, são muito submissos (E. 31), havia uma preocupação maior com as técnicas a realizar, roteiros a seguir (E. 33), a gente tentava se preocupar com o que eles sentiam, mas as técnicas eram mais focadas (E.45).

De uma maneira geral, as pessoas sentem medo do novo, do desconhecido, na enfermagem a relação vivida entre o aluno e o paciente e as descobertas do processo de cuidar no início da prática profissional são considerados como algo novo, causando ansiedade ${ }^{(14)}$.

Sabemos que por se tratar do primeiro estágio, o aluno não tem capacidade de enfrentar as barreiras que ocorrem no relacionamento com o paciente. Por isso, para ameni- zar a situação, a competência em comunicação faz-se cada vez mais necessária, pois somente assim é possível continuar oferecendo cuidado interdisciplinar, personalizado, competente e humanitário ${ }^{(15)}$.

\section{Descrevendo o relacionamento com o docente no campo de estágio}

\section{Bom relacionamento}

Os alunos consideraram que os professores eram prestativos, educados e pacientes. Relataram que sempre que solicitados tiraram suas dúvidas e inseguranças:

os professores eram prestativos, educados e pacientes. Em geral o relacionamento foi bom (E.4), com a professora o meu relacionamento foi bom, ela me ajudava no que não tinha segurança e me orientava como ajudar o paciente de uma maneira melhor (E.19, E.32), diante das minhas dificuldades no estágio, as professoras se mostraram bastante compreensivas, pude conversar bastante com elas e estas foram muito importantes para a minha continuidade do estágio (E-35).

\section{Relacionamento difícil}

Os alunos também relatam que as professoras se contradiziam muito em relação as dúvidas que surgiam. Referem que se preocupavam muito com as técnicas e não tinham paciência para ensinar:

[...] nossa relação era indiferente, mas todos percebiam que elas (as professoras) tinham preferências [...] (E.3), eram duas, e as duas se contradiziam muito. Tanto, que percebi que era melhor mostrar minhas anotações e solicitar correções apenas por parte de uma delas. Percebi que ambas gostaram de mim, fui bem avaliada, mas elas só se restringiam à perfeição das técnicas empregada (E.6), as professoras eram exigentes demais, implicantes e até meio desumanas (E.7), não foi muito frutífero, pois a professora algumas vezes mostrava-se impaciente e esquecia que era a nossa primeira vez em campo (E.10), pressionaram muito os alunos durante procedimento e muitas vezes não foram educadas (E.13), o professor no primeiro estágio, diferente de outros estágios, foi bastante opressor, chamava nossa atenção na frente dos colegas e pacientes de forma desnecessária, exigia detalhes das técnicas que hoje eu sei que não eram essenciais (E.16), as professoras ficavam muito em cima e eu não me sentia a vontade, não tinha liberdade e muitas vezes chamavam a atenção na frente dos pacientes (E.20), o relacionamento com a professora foi complicado, porque eu tinha receio de demonstrar dúvida ou insegurança. A professora não me passava tranqüilidade nem confiança, ela tinha uma postura austera e distante (E.29).

Em estudo realizado, alunos referem que se sentem acoIhidos pelo professor quando podem expor seus sentimentos em relação a situações difíceis enfrentadas por eles, assim, dialogando, o professor pode se fazer mais próximo do aluno, expondo também alguns de seus limites ${ }^{(16)}$. 
A comunicação professor-aluno torna-se, portanto, a base do processo de ensino e sofre influências do cotidiano de cada um de seus protagonistas. É importante que o professor valorize o diálogo, a troca, a relação interpessoal, acreditando que é possível aprender conversando, discutindo e trocando idéias com seus aprendizes ${ }^{(14)}$.

Acreditamos na necessidade de formar professores reflexivos para a prática docente na enfermagem, para que eles sejam capazes de refletir sobre sua própria ação cotidiana como formadores, de comprometer-se com a pesquisa, com sua formação e com seu desenvolvimento profissional| ${ }^{(17)}$.

É necessário que o aluno de enfermagem tenha a atenção dos educadores, sendo esperado que os professores estejam engajados nessas propostas e ofereçam aos alunos condições para alcançá-las, através de um aprendizado baseado em trocas ${ }^{(18)}$.

No desenvolvimento da aprendizagem, a posição que o professor assume na relação com o aluno deve ser alicerçada no respeito ao indivíduo, na confiança, na percepção do aluno como em ser integral, para que esse possa se perceber melhor como pessoa, passando então a perceber melhor os outros, e conseqüentemente, exercer melhor seu papel como pessoa e profissional|(19).

Os resultados do nosso estudo apontam o estresse e as contradições vivenciadas no primeiro estágio como parte do crescimento e aprendizado do aluno. Receber ajuda dos professores e colegas, perceber e acolher o paciente, orientar e avaliar a postura física diante das atividades rotineiras da equipe de enfermagem e auxiliar o paciente faz parte do processo de aprendizagem e estas situações passam a ser fonte de estímulo para sua construção de conhecimento na prática da técnica e nos relacionamentos.

\section{REFERÊNCIAS}

1. Carvalho MDB. Expectativas dos alunos de enfermagem frente ao primeiro estágio em hospital. Rev Esc Enferm USP. 1999;33(2):200-6.

2. Ângelo M. Vivendo uma prova de prova de fogo [tese]. Ribeirão Preto: Faculdade de Medicina de Ribeirão Preto, Universidade de São Paulo; 1989.

3. Ângelo M. Elementos componentes do contexto de interações na experiência de aprendizagem da aluna de enfermagem. In: Livro de Resumos do $2^{\circ}$ Simpósio Brasileiro de Comunicação em Enfermagem; 1990 ago.; Ribeirão Preto, BR. Ribeirão Preto: EERP; 1990. p. 334-47.

4. Valsecchi ASS, Nogueira MS. Fundamentos de enfermagem: incidentes críticos relacionados à prestação de assistência em estágio supervisionado. Rev Lat Am Enferm. 2002;10(6):819-24.

5. Braga EM. Competência em comunicação: uma ponte entre aprendizado e ensino na Enfermagem [tese]. São Paulo: Escola de Enfermagem, Universidade de São Paulo; 2004.

\section{CONSIDERAÇÕES FINAIS}

Os alunos evidenciaram o primeiro estágio como fonte de estresse e que a nova experiência em um campo desconhecido não permitia perceber possibilidades ou dificuldades naquele momento.

Reações comunicativas com sentimentos contraditórios são esperadas em relação ao ambiente físico e no que se refere a organização e planejamento de atividades quando do ingresso do aluno no ambiente de saúde, especialmente, quando a prática acontece em hospitais com altos níveis de complexidade.

Os alunos têm expectativas das oportunidades para exercer a prática, mas também esperam apoio e acolhimento da equipe de saúde, dos docentes e até dos pacientes. Sabemos que anseiam por espaços físicos adequados, por diálogo e acolhimento, mas nem sempre a prática da enfermagem acontece nestas condições, ou seja, muitas vezes os alunos se deparam com pacientes em que o cuidado exige esforço físico, com ambientes e situações estressantes, com contradições da teoria e prática, com dificuldades de relacionamento com pacientes, equipe e docentes, o que certamente causa sentimentos de ansiedade e insegurança.

Neste sentido entendemos como oportuno re-afirmar o professor como maior responsável por determinar o tipo de interação que haverá entre ele e o aluno e também por orientá-lo na condução dos relacionamentos com os pacientes e equipe de saúde, pois o aluno sente necessidade de receber apoio do professor e estabelecer um diálogo. Cabe ao professor ouvir, incentivar e capacitar-se para apoiar os alunos nas experiências iniciais da prática, para que esse primeiro contato seja um fator motivador para o aluno.

6. Bardin L. Análise de conteúdo. São Paulo: Edições 70; 1977.

7. Ciampone MHT, Melleiro MM. O planejamento e o processo decisório como instrumentos do processo de trabalho gerencial. In: Kurcgant P, coordenadora. Gerenciamento em enfermagem. Rio de Janeiro: Guanabara Koogan; 2005. p. 37-53.

8. Alexandre NMC, Moraes MAA, Mayayri N. Modelos de um curso de orientação sobre determinados aspectos ergonômicos e posturais no trabalho do pessoal de enfermagem. Rev Bras Saúde Ocup. 1991;19(1):61-4.

9. Chaves EC. Stress e trabalho de enfermeiro: a influência de características individuais no ajustamento e tolerância ao turno noturno [tese]. São Paulo: Instituto de Psicologia, Universidade de São Paulo; 1994.

10. Pereira MCA, Fávero N. A motivação no trabalho da equipe de enfermagem. Rev Lat Am Enferm. 2001;9(4):7-12. 
11. Pereira LL. Vivenciando a comunicação como descoberta [tese]. São Paulo: Escola de Enfermagem, Universidade de São Paulo; 1999.

12. Pichon-Riviére E. O processo grupal. São Paulo: Martins Fontes; 1991.

13. Braga EM, Sanguiliano LA, Silva MVG, Silva MJP. A comunicação em grupo entre profissionais de saúde. Nursing (São Paulo). $2004 ; 7(73): 36-41$.

14. Scherer ZAP, Scherer EA, Carvalho AMP. Reflexões sobre o ensino da enfermagem e os primeiros contatos do aluno com a profissão. Rev Lat Am Enferm. 2006;14(2):285-91.

15. Stefanelli MC, Carvalho EC, Arantes EC. Comunicação e enfermagem. In: Cianciarullo TI, coordenadora. A comunicação nos diferentes contextos da enfermagem. Barueri: Manole; 2005. p. 1-8.
16. Casate JC, Corrêa AK. Vivências de alunos de enfermagem em estágio hospitalar: subsídios para refletir sobre a humanização em saúde. Rev Esc Enferm USP. 2006;40(3):321-8.

17. Faria JIL, Casagrande LDR. A educação para o século XXI e a formação do professor reflexivo na enfermagem. Rev Lat Am Enferm. 2004;12(5):821-7.

18. Vasconcelos MLMC. Contribuindo para formação de professores universitários: relato de experiências. In: Masetto M, organizador. Docência na universidade. 4a ed. Campinas: Papirus; 2002. p.77-94.

19. Esperidião E. Holismo só na teoria: a trama dos sentimentos do acadêmico de enfermagem sobre sua formação. [dissertação]. Ribeirão Preto: Escola de Enfermagem de Ribeirão Preto, Universidade de São Paulo; 2001. 